\title{
TRANSFORMING ENGINEERING EDUCATION FOR THE 21ST CENTURY AS AN ENGINEERING R\&D WORK BY USING THE SYSTEMS APPROACH
}

\author{
Simo Lehto
}

Helsinki Polytechnic

\section{Changes created by globalization}

The paper describes the ongoing R\&D work in Finland aimed at developing and implementing a new structure for engineering education (EE). The work is driven by the fundamental changes created by the economic and cultural effects of globalization.

At the beginning of the $21^{\text {st }}$ century, most of the world is moving rapidly towards a global, market-oriented, real-time economy. This accelerating transition has led to a dramatically rising level of know-how and use of technology. Driven by continuing market liberalization, the transition continues at an accelerating rate. The increasing competition between companies forces routine manufacturing to be transferred to countries with low manpower costs. It also forces companies to adopt modern ICT tools (Information and Communications Technology) for automating routine work. At the same time, the global development is progressing towards the fulfillment of the basic human needs and, consequently, to the increasing emphasis of higher individual needs.

The new requirements produced by the increasing global competition and changes of societies can no longer be met by sporadic development. The situation forces organizations and people in the industrialized countries to make a fundamental transition: they must move from the routine (repetitive) operating mode to the systematic development (creative) mode. This shift demands a qualitative change in work methods, attitudes, organization, and management. In the global companies, the transition is being completed during this decade ${ }^{1}$.

\section{Routine work and development work}

The modes of operation of humans and organizations correspond to the three fundamental methods of human survival. They are maintaining the existing situation (repeating), improving the situation (developing), and removing the threat present in the situation (destroying). There are inherent differences between routine work and development work (and destructive work). The main purpose of routine work is to maintain a system in its present state. Routine work is generally repetitive and driven from outside. It uses existing knowledge and skills and lacks the tactical and strategic choices essential in development work. Much of routine mental work can be automated by means of modern ICT networks.

Development work means bringing a system into a better state through a path, which is unknown in advance. Development work in the real world involves differences of opinion, conflicts of interest, unexpected problems, errors, and temporary defeats. The proven means for successful development work is a goal-directed, systematic and creative, responsible, equal, long-term cooperation of selected, personally committed people, who possess the 
required knowledge and skills, outside information, tools, economic resources, and time. Development work requires continuous learning of new knowledge and skills. The work must be done on the different hierarchical levels of the target systems. It must also be done within physical, economical, environmental, legal, and ethical constraints.

The forms of cooperation include close personal relations, teamwork in small groups (teams), teamwork in larger groups and project organizations, mentoring relationships, and personal and professional networking. The success of development work strongly depends on the positive feelings of the people involved, such as enthusiasm, faith, joy of learning, pride, respect, trust, hope, love, excitement, and humor. The decisive factor in creative work is the inner energy of the people who do it.

The demanding recipe described has been used for sending twelve persons to the moon and returning them safely to Earth. It is the best-known way for succeeding in business, realizing personal dreams, and solving social problems.

\section{Changes of higher education in industrialized countries}

Social changes during the past decade have directly influenced the higher education including EE. During the 1990s, the education systems of industrialized countries have undergone great changes. The first is the shift from elite to mass education. In Finland, national plans call for over $60 \%$ of the annual age group to be educated to the tertiary college level. The resulting competition within higher education has led to the continuous assessment of the educational organizations by the government and accreditation institutions. These changes have also led to increased competition between EE organizations for high-quality students and faculty.

The expansion of higher education raises the average know-how level of the country and also affects the characteristics of the students. Present-day youth no longer follow the classical ideologies or conventions of the societies. At the same time, the students are strongly influenced by advertising and media. This has also changed the status of education: the youth do not see it as the only way to success in life. These changes have had a distinct effect on the know-how level and they have increased the heterogeneity of the students entering EE.

\section{Importance of engineering in global transformation}

Globalization directly impacts the engineering profession. Meeting the needs of societies in the global competition of the $21^{\text {st }}$ century emphasizes the role of engineering and increases the requirements for engineers. The engineers play a central role in the social transformation, e.g. by being instrumental in transferring human routine work to man-made machines and systems. High-quality EE is very important to all nations, particularly small countries such as Finland, which have a strong focus on high-tech industries. These industries depend on the excellence of the engineers in the global competition. For the same reasons, high-quality EE is essential to the future of developing countries.

\section{Structure and organization of current EE}

The situation during this decade places new demands on the EE organizations for deeper learning, more efficient and innovative teaching, more responsibility for student employment and career success, and responsibility to society. In the field of education, the transition to the development mode is still at its infancy. The profound changes in societies and the dramatic 
developments of technology have had relatively little effect on the structure of the EE. Most of the current EE organizations and programs have been implemented in slowly changing routine societies (e.g. army, Taylorism, Industrialism). The current EE model is based on the classical education structure, which has evolved (not systematically developed) for a static society over a number of centuries. The curriculum of most EE institutions in the world goes back to the curriculum implemented in the USA in the late 1940s.

The structure has been maintained even when the complexity of the world has increased and the technology has changed dramatically during the late $20^{\text {th }}$ century. The mode and organization of EE institutions still correspond to the industrial era (assembly line) mode. The structure of the current EE is intrinsically based on the division of the world into specialized disciplines and subjects. The curriculum is partitioned into separate courses and the learning is controlled by means of individual written tests. This has led to a fragmentation of the content, the work of people involved, and their use of time.

Most of the content presented is based on the model world e.g. textbooks and theories. This separates the learning from the real world (e.g. work of the engineer). The emphasis of the present EE is on quantity, aiming at including and presenting everything an EE student needs during his/her career. This way of doing things has led to overloading and incoherence and the lack of the ability to combine knowledge into functioning wholes in the real world ${ }^{5}$.

It is important to realize that the situation is not due to the deficiencies of the educators or the teachers. In fact, the present model has become a barrier for individual teachers for improving their work, making it impossible for the teachers to meet the new demands. The goal of the development of the new EE, therefore, must be to change the EE organizations to the development mode and the flat (entrepreneurial) organization.

\section{Need for restructuring current EE}

National education systems have the responsibility to drive the fundamental transitions in industry and society. They have to take into account the changes affecting the society over a long period of time. Most of the students entering EE institutions in 2004 will be professionally active in 2050 .

This inherent structure of the present EE inhibits the change of the EE institutions needed for meeting the demands imposed by the industry and the society. The disparity between the new requirements and the deficiencies of the present $\mathrm{EE}$ has created a strong need for the restructuring of the EE. During the 1990s, the need for a major change in EE has been emphasized in Europe and the USA ${ }^{6}$.

During the past decade it has also become clear that the discrepancy between the education organizations and their corporate customers can no longer be solved by means of partial solutions within the present operating mode: e.g. adding subjects/courses/projects/work practice, adopting new teaching methods, and exploiting new technology. The situation can only be remedied by changing the present EE to incorporate a new structure. At the same time, dramatic advances of ICT offer great possibilities.

In the following chapters, a thorough theoretical analysis is presented. The reason is that the understanding the basic ideas and the approaches used in the work logically leads to the transformation of the structure of EE and to the new model for EE. 


\section{Systems engineering approach}

The classical scientific approach divides the world surrounding the human beings into a large number of separate scientific disciplines and sub-disciplines. The systems approach tries to manage the extreme complexity of the world by treating the world as a collection of functional entities (dynamical systems), which consist of material, energy, and information and by describing these systems with the best models available ${ }^{2,3}$.

Science is human activity (work of people) that extracts knowledge from the world surrounding humankind and packages it into useful external models. It is driven by the inherent human curiosity and the need to make the world a better place to live.

Engineering is the human activity (work of people) that improves (mainly) the physical world for the human beings. It is driven by the inherent human creativity and the need to make the world a better place to live. Comparing meteorology to (emerging) weather engineering clarifies the closely intertwined but different orientation of science and engineering.

Technology is the combination of the concrete and abstract tools available to the human beings in this work.

In systems engineering, complex real-world systems are usually described as hierarchical (multilevel) systems. The systems are separated into subsystems. Accordingly, the structure and operation of the systems can be separated to the operational level (how), tactical level (who, what, where, when), and strategic level (why) connected with the goals of the system.

\section{Model thinking}

All human life is based on using mental models (representations or "knowledge packages" located in the brain) for describing the world and responding to the events of the world. In addition to these mental models, the humans also use a number of external models (information located outside the brain) for exchanging information and influencing behavior.

Examples of the categories of external models are verbal models (e.g. spoken languages), visual models (e.g. symbols, characters, graphics, still and moving 2-D and 3-D pictures), analog models (system as model for another system), mathematical models (information presented in an unambiguous universal man-made language), and computer models (models of the external models stored and processed in fast electronic form = electronic models).

One of the fundamental reasons for the deficiencies of the present EE is the underlying conscious or unconscious model for the human being, most importantly the student. In the current EE solution, the model for the human being is a physical (nonliving) object. The student is regarded e.g. as a vessel, a partially filled cup or a machine or computer. The goal of the present EE model is to fill all students with a similar knowledge to last their whole lifetime. The teachers are understood mainly as dispensers for filling the cups.

According to systems thinking, the human beings involved in the EE (students, teachers, specialists etc.) are modeled as complex dynamical, parallel, and hierarchical systems, which have a genetically programmed internal control system. This system operates according to the genetic program under the strong influence of the environment and continuously directs the life of the human being towards the internal personal goals. 


\section{Analogies used in R\&D work}

The mode of operation and the organization of large, medium-sized, and small global customer-driven corporations have been used as the main analog models in the development of the new EE model. The methods of doing things in these development organizations have been used as models and tools in the optimization of the new EE solution. Examples are JIT, TQM, and lean production methods that have greatly improved the efficiency of manufacturing mass products. The ideas of mass customization, modularization, and outsourcing are also important in the optimization of the new EE solution.

For the purpose of developing a new EE solution, an EE organization can be regarded as a customer-driven service company and the EE provided by the organization as a service product, which has multiple customers. The analogy of an EE organization to a company, however, has deficiencies. Most physical products are entirely passive. Many service products also require little activity from the part of the customer. Learning, however, depends decisively on the active long-term participation of the student in the learning process. Therefore, students can be considered as the first clients (active long-term cooperative customers). The industry, that employs and pays the salaries of the engineers, can be thought of as the second client of the EE organizations.

\section{R\&D work in Finland}

The goal of the work in Finland is to develop and implement a new EE solution that meets the requirements of the complex global environment. The complexity of the development of the new structure requires a systematic theoretical approach. The work has been done as an engineering endeavor as a parallel combination of theoretical and experimental work, utilizing a new approach based on systems and model thinking.

The ongoing work in Finland is based on the ideas and initial work done in engineering education at the University of Oulu in Finland during 1975-76. The basic structure of the student-driven real-world education has been developed and tested in the continuing EE and entrepreneurial education of the University of Oulu during $1978-83^{7}$. The ideas published in the early 1970 s have decisively contributed to this work $^{8,9}$.

The R\&D work towards developing the new solution has been done as an engineering endeavor since 1993. The new approach to EE has been developed in 1993-97 at Kymenlaakso Polytechnic in southeastern Finland. During 1998-99, the structure of the new model has been developed in an R\&D project funded by the Ministry of Education in Finland and the European Union ${ }^{10}$. Parts of the new model have been pilot-tested during 1997-99 at the Department of Mechanical Engineering at Kymenlaakso Polytechnic.

Since 2000, the development and implementation of new EE model has been continued at Helsinki Polytechnic. Since August 2001, the model has been pilot-tested with three groups of students at the new Program of Industrial Management, which leads to the M.Sc. degree as a European cooperation. A team of some 25 faculty members participates in the work.

\section{Learning goals for new EE}

The new EE model developed in Finland is based on the definition of the competence requirements for the engineer working in the global environment. These requirements can be 
summarized as the capability to do efficient engineering work in a selected engineering field in the international environment and to have a successful engineering career. The emphasis of the goals is on learning the engineer's systematic and creative way of thinking and doing things in the real world. According to the systems approach, the learning goals for the whole learning period can be divided in the following way.

-Profession of the engineer (selected field of engineering, engineering in general)

-Objects of engineering work (non-living world, organizations, enterprises)

-Engineering work (development work, global economical, environmental, legal, and human constraints)

-Working environment of the engineer (selected field, human being, organizations, market economics, business)

-Modern tools of engineering $=$ technology (abstract tools $=$ mathematics, concrete tools $=$ modern ICT and mechanical machines)

-Personal development (specializations, continuous learning and professional development).

\section{Structure of new EE}

The new EE model resulting from the work in Finland can be summarized as a shift to insidedriven, individual total learning in the real world. The new model is based on achieving the learning goals for engineers derived by the EE organization in cooperation with industrial partners. The main method is the systematic and creative long-term cooperation of the students and the teachers/specialists on an equal human level.

The new approach places the main emphasis on the individual learning processes of the students. The mode of learning can be defined as "learning by doing and experiencing". The main building block of the new model is a learning project connected with the real world. It is a task performed by the student designed to produce required learning results. A learning project is divided into learning tasks.

A sequence of real-world learning projects is used as the vehicle for creating an effective learning environment for supporting and guiding the student's individual learning processes during the whole study period. The themes and contents of the projects are selected, formulated and coordinated to meet the learning goals: the learning goals are imbedded in the learning projects. The sequence starts with relatively small-scale learning projects and approaches real-time projects from the industry/society during the study period. Participation in a real engineering project during the first year gives an important foundation for the following years. During the second semester the students use approximately half of their time to carry out an industrial project from a partner company/organization. Individual learning projects are included in the project sequence during the whole learning period.

During the design and implementation, the project sequence is continuously optimized on the project level and the sequence level by selecting, formulating and coordinating the themes and contents of the projects. Examples are projects connected with the personal life of the students, media events, achievements of engineers, development projects of the teachers and faculty members, projects from cooperating companies and organizations, practice/internship, study periods abroad, personal specialization, entrepreneurial projects and the thesis work.

The new kind of EE model provides the needed flexibility for selecting and formulating the learning project sequence together with the local industry. This optimization is based on a 
direct feedback from the students, teachers and industry. This method is consistent with the meet in the middle approach in systems engineering, which combines the details (operational level) with the whole (strategic level) on the middle (tactical) level.

A process of learning projects running throughout the total learning period concentrates on the work of the engineer. It helps students to grow into engineers by describing the fundamentals of the engineering profession and providing real-world examples. The aim is to provide a model of the engineering profession from the first year in order to facilitate the personal process towards becoming an engineer. Seeing a picture of a jigsaw puzzle greatly facilitates the assembling task. Experience shows that the first year is the most important year, requiring the best teachers with human skills and deep understanding of engineering.

All the practical forms of cooperation used in the successful development work are used in the learning and the cooperation between the students and the faculty. As an example, the students start their work in groups of three students during the first semester and start working in larger groups and project organizations during the industrial project during the second semester. The experience shows that continuous change of groups and group characteristics is needed during the whole study period.

In a similar way, team and project organization is used for the cooperation of the teachers. Each learning project has a project manager who manages and coordinates the work of the faculty and staff members assigned to the project within the resources allocated.

The experience during the development of the new model has shown that the individual learning processes of the students must be measured in real-time. The measurements are performed e.g. by means of compact tests included in the learning tasks and projects. This type of continuous real-time feedback forms an essential foundation for the effective cooperation between the students and the teachers and makes it possible to support the students on an on-demand basis. One of the main objectives is to allocate as much resources as possible for the continuous personal interaction of the faculty/staff members with the students. Therefore, the operation maximizes the personal contact with the students, which produces most of the deep learning (added value).

As part of the new model, the basic knowledge needed in the learning projects is made available to the students as effectively as possible. The main method is to give compact lectures ("information flashes") for the whole student group. They are given by the faculty members or outside specialists assigned to the learning project. The "flashes" contain timely information relevant to the project. Because the learning projects are not divided into subjects (similar to real-world engineering projects) the effective lectures typically include information from multiple classical disciplines/courses. The "flashes" also include examples and exercises that make it easier for the students to understand and carry out the projects. The lectures are driven in real time by the demands of the project. The "flashes" are delivered during a weekly slot allocated to the project. The timing decisions are based on the direct feedback from the teachers and the representatives of the student group. In practice, this is done in weekly faculty/staff meetings where the student representatives participate. The ondemand lecturing increases the motivation of the students and teachers and improves the effectiveness of the new model. In addition to the compact lectures, selected material in books and on the Internet is also included in the project material. The multiple methods used in the teaching correspond to the different learning styles of the students. 
The continuous process also contains a personal mentoring system. Selected teachers of the student group, who are interested in the human being, function as a team of mentors.

Mentoring is based on a personal contact with the students and on real-time feedback through the feedback system. This arrangement allows the mentor to support the student in case of difficulties and temporary problems. The mentoring effort in concentrated to the first and last year, when the need for the personal support is greatest.

\section{Integrated assessment system}

The assessment system integrated into the new structure is divided into two components: the system for learning self-assessment and the system for grading. Self-assessment is continuously used to evaluate the learning processes of the students by providing direct feedback from the teachers and fellow students as natural part of the cooperation. The second component for the individual grading of the students is based on the evaluation of the individual outcomes of the learning projects. The students present the outcomes of the learning project to a teacher as a justification for their grades. The evaluation is mainly done during private and public personal discussions between the teachers and the students. These meetings take place during the learning tasks and at the end of the learning projects. They also provide the personal feedback, which has been found to be very valuable to the students.

\section{Role of modern ICT}

Modern ICT is used as a central tool in the development of the new EE solution. It is systematically used for the automating the routine part of the work. This includes e.g. the delivery of basic material to the students, weekly and daily scheduling, and the practical arrangements for the grading of the students. Experience has shown that modern ICT is the only way to control and coordinate the complex operation and organization of the new EE.

\section{Comparison with other EE models}

Because the world is inherently interdisciplinary, in the new model there are no divisions to subjects and courses or to theoretical or professional subjects. The use of learning projects connected with the real world removes the need for integration because the projects are not differentiated to disciplines or subjects. The content needed for obtaining the learning goals can be embedded into the learning projects in a natural way by selecting and formulating the themes and contents of the projects.

The new way of doing things converts the basic task of the teacher from presenting his/her subject matter to making the students learn the required knowledge and skills in cooperation with other teachers. It frees the teachers from routine presentation of information and makes them coaches (mentors or leaders) for the students. The new model also has the flexibility for choosing the tasks of the teachers and faculty according to their personal skills and interests.

\section{Potential advantages of restructured EE}

The ongoing work in Finland done since 1993 has produced deep learning in the field of EE, which is important for the restructuring of EE in Finland and other countries. The potential advantages of the new model are based on the combination of the theoretical results and experimental experiences accumulated during the pilot-test phase in 2001-04. During 200406, the testing and implementation of the new solution will be continued at the Program of 
Industrial Management as a systematic long-term engineering R\&D effort with partners from industry and EE organizations. During this time, the results will be used to elaborate and confirm the advantages presented in this paper.

The main result of the work in Finland is to make the mode of operation and the organization of the EE institutions correspond to those of modern international companies ${ }^{11,12}$. This change minimizes the barrier between the EE institutions and the industry and eliminates the discrepancy between education and modern work life. In practice, this means that the young engineers studying in the new way can not graduate without having the fundamental skills needed in modern engineering, e.g. skills in team work and project work, self-confidence, responsibility, innovativeness, and creativity. These fundamentally important skills cannot be taught in the current way e.g. by adding separate courses. They can only be learnt by doing and experiencing. In the new model, they are intrinsically embedded in the mode of operation.

For the nations, the new model naturally brings about systematic long-term cooperation between the education organizations and industry and directs the EE institutions towards producing active innovative people for the benefit of the nations in the global competition.

For the industry, the new model promises to produce higher-quality engineers: young engineers "with the latest know-how and long experience in industry." These types of engineers are particularly valuable for the companies operating in the international markets. Initial estimates are that the engineers would be productive to the companies 1-2 years earlier than the engineers studying in the current mode.

For the students, the new EE model offers more effective and rewarding learning and real personal electiveness. The internally-driven process naturally enhances the self-knowledge and personal strengths of the students, directs the students towards employment or an entrepreneurial career, and forms a natural start for a successful career in engineering.

For the EE organizations adopting the model, it would provide benefits in the competition for high-quality students, faculty and staff and lead to more efficient utilization of resources, including the know-how and creativity of the people of the faculty. The new mode of operation combines the government-assigned tasks of the university in a natural way.

For the faculty members/teachers, the model makes the work more rewarding and enjoyable. It naturally directs the teachers towards cooperation and becoming coaches/mentors/leaders and enhances continuous professional development.

The new model is also applicable to continuing EE, continuous professional development, and other fields of technical education. The restructured EE represents an example of the fundamental reengineering of professional and academic education for meeting the new needs of the societies in the global environment.

\section{Acknowledgments}

The author is grateful to the Management of Helsinki Polytechnic and the Faculty of Engineering for the unique possibility for carrying out the work. The results summarized in

this paper have become possible only through the contributions and support by the leadership and members of the development team of the Program of Industrial Management. 


\section{Bibliography}

1. Kautto-Koivula, K., Huhtaniemi, M, Evolution towards Human-Centric Knowledge Society. Can Societies Learn from Global Corporations?, Global Peace through the Global University System, Tapio Varis, Takeshi Utsumi, William Klemm (eds.), (RCVE), Hämeenlinna, Finland (2003).

2. Lange, O., Wholes and Parts - a General Theory of System Behaviour, Warszawa, Pergamon Press PWNPolish Scientific Publishers (1962).

3. Von Bertalanffy, L., General Systems Theory, New York, George Braziller (1968).

4. Wilson, E.O., Consilience, New York, Alfred A. Knopf, Division of Random House, Inc. (1998).

5. Virkkala, V., Creative Problem Solving (in Finnish), Vammalan kirjapaino, Finland (1994).

6. Bordogna, J., Fromm, E., Ernst, E.O., Engineering Education: Innovation Through Integration, Journal of Engineering Education, January (1993).

7. Lehto, S., Non-traditional courses at the University of Oulu - an Experience in Developing Relations Between the University and the Surrounding Region. Proc. Standing Conference of Rectors, Presidents and ViceChancellors of the European Universities, Bergen, Norway (1983).

8. Miles, R.B., Kimball, R.B., Frey, W.H., The Engineer as a Radical, IEEE Transactions on Aerospace and Electronics Systems, July (1971).

9. Golomb, S.W., Mathematical Models - Uses and Limitations, Aeronautics \& Astronautics, Jan (1968).

10. Lehto, S., Yrittäjyyden ja hautomotoiminnan kehittäminen, ESR-loppuraportti opetusministeriölle (in Finnish), Kymenlaakson ammattikorkeakoulu 1.3.1999, projekti 990061(1999).

11. Lehto, S., A New Solution for Global Engineering Education in the $21^{\text {st }}$ Century: a Structural Transition to Internally driven Individual and Total Learning by Means of an Optimised Process of Real-world Learning Projects, Proc. $4^{\text {th }}$ UICEE Annual Conference on Engineering Education, Thailand (2001).

12. Lehto, S., Transforming Engineering Education from the Maintaining Mode of Operation to the Development Mode of the Global Industry, Proceedings of $31^{\text {st }}$ SEFI Conference, Porto, Portugal (2003).

\section{Biography}

Simo Lehto's experience includes three decades of work in scientific research and teaching and education development in higher professional and academic education. The experience also includes management and organizational development, entrepreneurship, and high-tech $\mathrm{R} \& \mathrm{D}$, product development and marketing.

Simo Lehto received the degrees of MSc. Eng. (Control and Systems Engineering) in 1967 and Lic. of Tech. (Control and Systems Engineering and Wireless Communications) in 1970, from University of Oulu, Finland. He was Acting Professor (Theoretical Electrical Engineering, Control and Systems Engineering) at University of Oulu in 1970-73 and 1975-78. During 1978-83 he was developing and managing the Further Education Organization (Engineering Education and Entrepreneurial Training) at University of Oulu.

At University of Oulu his research fields were industrial process dynamics, electronics, and wireless communications. During 1973-1975, he concentrated on product development for a high-tech company. During 1984-1990 he was a private entrepreneur and carried out product development for wireless communications. Simo Lehto joined Kymenlaakso Polytechnic in 1991 as Lecturer of Physics and Mathematics and teacher in Entrepreneurial Education until 1997. During 1998-2000 he was Project Manager for the development of Engineering Education. After joining Helsinki Polytechnic in 2000, he is now Project Manager for the development of Engineering Education. 